\title{
The Impact of Task-based Approach on Iranian EFL Learners' Motivation in Writing Research Abstracts
}

\author{
Masoud Khalili Sabet \\ English Department, University of Guilan, Rasht, Iran \\ Abdorreza Tahriri \\ English Department, University of Guilan, Rasht, Iran \\ Eshrat Bazarmaj Haghi (Corresponding Author) \\ English Department, University of Guilan, Rasht, Iran
}

\begin{abstract}
Writing as a complex activity requires systematic attention to motivational conditions (Bruning and Horn, 2000). This study aimed at examining whether there is a relationship between EFL learners' motivation and their performance in writing research abstracts as well as the impact of task- based approach on the participants' motivation. For these aims, sixty-eight EFL university students at intermediate level of proficiency participated in this study. Thirty-two of the participating students were involved in the class based on Task-based Language Teaching (TBLT) where three phases of pre-task, task- cycle and post-task as suggested by Swan (2005) were used and students had the opportunity to do tasks in groups. Thirty-six of them participated in Presentation-Practice-Production (PPP) approach where the teaching was divided into presentation, practice and production phases and students had to do the activities individually. After receiving treatment for eight sessions, students were asked to write an abstract for a research article. Furthermore, a motivation questionnaire adopted from Lam and Law (2007) was distributed among the participants which included the following motivational constructs: challenge, real life significance, curiosity, autonomy; recognition and evaluation. The findings demonstrated that students' motivation is positively related to their abstract writing performance. Moreover, results of Independent-Sample T- Test showed that Task-based approach was motivating for the students. Therefore, the data suggested that students with higher motivation can have better performance in writing abstracts and students' motivation can be enhanced by the teaching approach in use. Finally, several implications that may help guide future research are offered.
\end{abstract}

Index Terms - TBLT approach, PPP approach, motivation, motivational constructs, EFL learners

\section{INTRODUCTION}

Abstract as the first subgenre of a research article gives a concise summary of the whole paper. In order to publish research paper in journals or present it in conferences, students need to send the research abstract. As a result, writing research article abstracts is of relevance to the learners' real world academic needs. However, still many students have difficulty in writing research abstracts.

According to Dörnyei (1998) even individuals with remarkable abilities cannot accomplish long-term goals without sufficient motivation. Since motivation is one of the key factors in language learning, in this study relationship between students' motivation and performance in writing of abstract was explored. Moreover, it is attempted to investigate the impact of task-based approach on the participants' motivation and see whether the task-based approach is a motivating approach for the students. By a 'motivating approach' we mean an approach in which teachers provided students with tasks which are challenging, used activities which are related to the real world, made them curious in learning new things, gave them enough autonomy, praised their efforts and gave them useful feedbacks (Lam and Law, 2007). Among the teaching approaches available, we decided to focus on TBLT because it is a new approach in Iran and needs more investigations. The participants were two groups of University students enrolled in research course at Guilan University .The experimental group received teaching based on TBLT where the teaching was divided to pretask, task-cycle and post-task phases and students had the opportunity to do tasks in groups and the control group received teaching based on Presentation-Practice-Production (PPP) where the teaching was divided into presentation, practice and production phases and students had to do the activities individually. During the classes it was attempted to introduce Hyland's (2000) five abstract moves to the students which were namely introduction, purpose, method, result and conclusion. Finally, students were asked to write an abstract for a research article and complete a questionnaire about their motivation towards the teaching approach they had received. 


\section{LITERATURE REVIEW}

\section{A. TBLT and PPP Approaches}

Proponent of TBLT varies in their beliefs about TBLT. However, Swan (2005) has mentioned some of the key principles in TBLT. He stated that the meaning-driven language learning happens in TBLT approach. It means that the main focus of learners should be on the meaning of the language. However; by emphasizing the meaning he did not neglect the importance of the form of language and its learning. He believed that peripherally learners should also pay attention to the form in order to understand the meaning better .For this aim he mentioned that in pre- or post-task phases the formal features of language should be worked on. He also emphasized the necessity of intervention for the purpose of fostering the acquisition of formal linguistic elements, and at the same time retaining the advantages of an approach which is 'natural'. Moreover, he mentioned that learners have an important role in the TBLT approach and the teacher is not the whole authority in the classroom. He also emphasized the usage of communicative tasks. Swan (2005) also indicated that, the strength of TBLT approach, comparing to the traditional approaches, is on its focus on communication. Furthermore, the common design of a task-based lesson according to him is consisted of three principal phases namely pre-task phase, task- cycle phase and post-task phase.

Since the term 'task' is the main concept in TBLT, it is better to define it first. Different scholars have given different definitions of this term. According to Nunan (2006), it is a part of classroom procedure to convey meaning. Moreover, Skehan(1996) defined task as an activity in which meaning, task completion ,the real-world and outcome are focused. Willis defines task as an activity which has a central goal and a real outcome (as cited in Murad, 2009).In this article what we mean by the term task is more closed to the definition given by Prabhu as "An activity which requires learners to arrive to an outcome from given information through some processes of thought and which allowed teachers to control and regulate that process" (1987, as cited in Murad, 2009, p.37).

Since in this research in one of the classes tasks were used and in another one traditional activities were focused, it is better to distinguish tasks from the traditional activities. Ellis (2009) mentioned that a task must have these criteria: the main focus of it should be on meaning, some kind of gap should exist, for completing an activity learners should basically rely on their own knowledge and rather than relying on the use of language, the task has a clearly defined outcome. And based on such criteria, he made a distinction between a 'task' and a 'traditional activity'. Whereas an activity may satisfy the second and the third criteria, it does not satisfy the first one.

Willis (1996, in Murad, 2009, p. 40-41) listed the following types of tasks in TBLT:

-listing tasks: these types of task include brainstorming and fact-finding, the outcome is a completed list or draft mind map.

-ordering, sorting tasks: these types of task include sequencing, ranking and classifying. The outcome is a set of information ordered and sorted according to specific criteria.

-comparing tasks: these types of task include matching, finding similarities, or differences.

-problem solving tasks: this type of task includes analyzing real situations, reasoning, and decision-making.

-sharing experience tasks: these types of tasks include narrating, describing, exploring and explaining attitudes, opinions and reaction.

-Creative tasks: these types of task include brainstorming, fact finding, ordering and sorting, comparing and many other activities. The outcome is an end product that can be appreciated by a wider audience.

Since it was not possible to work on all types of available tasks, in this study we focused on problem- solving tasks.

The steps of the PPP model can be summarized as follows: presenting new language item by the teacher, practicing the items by the learners through some kinds of activities such as drills, individual and choral repetition, and at last producing the language for themselves (Byrne,1986, as cited in Carless, 2009, ) .

TBLT has its own pros and cons. Canilao (2009) who is a follower of this approach stated that "Writing becomes a more essential learning experience and a fulfilling pedagogical undertaking through activities designed on TBLT principles" (p.2). He also mentioned that one of the advantages of TBLT is that it prepares the ground for designing tasks in which process writing and group work can be incorporated.

However, there are some scholars who have criticized task-based approaches. For instance, Swan (2005) argued that in case of having a limited classroom time and minimal out-of-class exposure, task-based approaches are not appropriate. Moreover, according to an article written by Adams and Newton (2009) there are some challenges that language educators may face in implementing TBLT in Asian contexts.

According to Vystavêloà (2009) PPP model provided a clear and simple structure of the lesson, the lesson is easy to prepare, the materials used for it are ordered from simplest to the most difficult, the activities are arranged from the most controlled to the least controlled and also the teacher can see the progress of the students. Moreover, Skehan (2003, in Carless, 2009) stated that one of the strong points of this model is providing a clear teacher role. Moreover, considering the EFL context, still many Asian school teachers prefer using PPP approaches (Tang, 2004, Tong, 2005, as cited in Carless, 2009).

However, the PPP approach has its own skeptics. Willis (1996, in Izadpanah, 2010) pointed out that the learners often fail when communicating. Skehan (1996, as cited in Izadpanah,2010)also argued that the Presentation, Practice, Production of material do not always line up because the students do not learn the new items in the same order in which they were presented to them. Moreover, Vystavêloà (2009) mentioned that the disadvantages of this approach are as 
follows: students tend to be passive quite a large part of the lesson, the lessons are predisposed to be teacher-centered and the lesson structure is predictable. Also, it was assumed that in PPP approach the main focus is often on accuracy rather than fluency (Thornbury, 1999, as cited in Carless, 2009).

\section{B. Previous Studies on Motivation}

Although the word motivation is commonly used in everyday language, in scientific context it is not easily defined. In spite of the existence of various definitions of the term motivation, in this paper it is defined generally as "the preference to do certain things and to avoid doing others" (Hannula, 2006, as cited in Waege and Pantziara, 2010). The word motivation derives from the Latin movere, "to move" (Hidi and Boscolo, 2007). Therefore, it can be said that writers are moved to write, and they attempt through their writing to move their audiences.

Starting from the late 1980 s, researchers focused on the role of motivation in learning specific domains, including writing (Hidi and Boscolo, 2007).Many researchers have emphasized the importance of motivation in learning. With regard to the status of language teaching in Iran, Bakhshi (1997) noted: "one of the problems is an old belief that just knowing about language and its grammatical patterns suffice teaching English, so there is no room left for advancement through insight of linguistics, psycholinguistics, sociolinguistics, methodology, and pedagogy" (p.14, as cited in Keihanyan, 2009).Therefore, motivation in language learning as one of the psychological elements should be more investigated in Iran. According to Dweck (1986) "It has long been known that factors other than ability influence whether learners seek or avoid challenges, whether they persist or withdraw in the face of difficulty, and whether they use and develop their skills effectively" (p.1040). Gold (1959, as cited in Ripple, 1965) also mentioned that the student's position in socio-emotional structure of the classroom, the relationship of student with his teacher and classmates, can influence his motivation. Boekaerts (2002) stated that the students try to make sense of novel learning situation by referring to their motivational beliefs. He defined motivational beliefs as "opinions, judgments and values that students hold about objects, events or subject matter areas" (p.8).He explained that these opinions can be about the effectiveness of learning and teaching method.

Several studies about motivation and its effect on students' learning have been conducted. Boekaerts (2002) stated that what differentiated successful students from less successful ones is having a clear idea about their goals. He explained that these students perceive some learning settings as supportive for teaching them. A research which was done by Schmidt and Frota (1989, as cited in Kassabgy, Boraie and Schmidt, 2001) can support this claim. According to their study it was found out that while teachers accepted the value of communicatively oriented activities, the learners placed a greater value for traditional ways of teaching which supports traditional, teacher-centered, grammar focused class. The reason was that the learners who were motivated to learn English only to pass a state exam may regard communicatively oriented classes as an inappropriate approach for reaching their goals.

Former studies have revealed that a meaningful relationship exists between motivation and students' performance. Juvonen and Wentzel (1996, as cited in Wentzel and Wigfield, 1998) asserted that "recent evidence suggests that students' social motivations influence their academic performance" (p.156).Some researchers have studied the influence of Students' motivation on their performance in learning different parts of language. Schmidt (1993, as cited in Keihanyan, 2009) argued that students who are motivated pay more attention to the language input compared to the less motivated students. Moreover, Niezgoda and Röver (2001, as cited in Keihanyan, 2009) mentioned that motivated learners are more sensitive to grammatical errors. Cook (2001, as cited in Takahashi, 2005) also pointed out that learners who are more motivated can notice pragmatic functions of language. Moreover, Tateyama (2001, as cited in Takahashi, 2005) found that learners who are highly motivated demonstrated better performance in role plays.

Some researchers also have studied how different teaching practices influence Students' motivation. Rosenholtz and Simpeson (1984, as cited in Wentzel and Wigfield, 1998) reported that the kind of instructional practices affect Students' motivations. Since some practices can increase the salience of extrinsic motivators and ego-focused learning goals or can lead students to focus more on their perceived competence rather than an incremental condition and therefore reduce the quality of academic motivation. McClintic (1989) attempted to document motivational differences that may be associated with two approaches to classroom writing instruction namely process-oriented approach and product-oriented approach. Motivational constructs considered in the study included:1)entity(ability is stable)versus incremental(ability increases with effort)theories of writing ability;(2)initial importance of mechanics versus content;(3)confidence;(4)intrinsic motivation;(5)utility value; and (6)perceived competence. According to the results, it was concluded that motivational factors may be instrumental in mediating students' actual performance of writing tasks in the classroom, and motivational consequences may differ as a result of process and product oriented approaches in writing instruction. Lam and Law (2007) explored the roles of instructional practices on motivation. The teachers taught the students how to write an expository essay during three sessions. After the students completed the essay, a questionnaire was distributed to investigate their motivation in the task and how they perceived the instruction. The findings indicated that more motivating teaching strategies leads to more motivated students.

\section{RESEARCH METHODOLOGY}

\section{A. Research Context and Research Questions}

In this study, it was attempted to shed some light on the following questions: 
Research Question 1) What is the relationship between the students' motivation and their performance in writing research article abstract?

Research Question 2) What is the effect of TBLT on students' motivation in writing research article abstract?

Accordingly, the following null hypotheses were formulated for the research questions:

H1) No relationship exists between the students' motivation and their performance in writing research article abstract.

H2) TBLT has no effect on students' motivation in writing research article abstract.

\section{B. Research Participants}

Sixty-eight students participated in this study . They were studying English Language and Literature at University of Guilan. They participated in the classes for ten sessions. They were enrolled in the research class and met once a week. Since abstract writing is related to research writing, with the permission of the professor, in the last 45 minutes of the class the students received instruction about abstract writing for ten sessions. They were all at intermediate proficiency level and were divided into two classes. The first class, consisting of 36 students (20 female students and 16 male students), received the instruction based on the PPP approach. The second class, consisting of 32 students (19 female students and 13 male students) received the instruction based on the TBLT approach.

\section{Instruments}

The instruments used for this study consisted of a proficiency test, a pre-test, a post-test, two types of tasks, three types of activities and a motivation questionnaire.

a) Nelson Proficiency Test (B) at intermediate level was employed to estimate the homogeneity of students regarding their knowledge of general English. We used the test at intermediate level because this was the level suggested by the students' professors.

b) A research article named "EFL teachers' perceptions of Task-based language teaching: with a focus on Korean secondary classroom practice", Jong (2006) was utilized for the post -test. The students were required to read the whole paper and write an abstract for it.

c) Two types of tasks, which were checked by two university professors, were used in the class which was taught based on TBLT. In one of the tasks, students were asked to find the extra information in abstracts. In the other one, they were asked to find mistakes such as not having one of the moves of abstracts.

d) Three types of activities were used in classes based on PPP approach. The activities were also checked by two university professors. In the first one students were asked to find different moves in the abstract. In the second one they were asked to put abstract moves in correct order. In the last type they were asked to different moves for an abstract, this was used in the production phase of the classes.

e) A questionnaire adopted from a recent research by Lam and Law (2007) was used for the purpose of finding out which of the two approaches is more motivating for students in each class .The questionnaire consisted of 18 items aimed at measuring the students' perception of the extent to which their teacher provided them with tasks that are challenging, used activities which are related to the real world, made learners curious in learning new things, gave them enough autonomy, praised their efforts and gave them useful feedbacks. The students were asked to indicate to what extent they agreed to the 18 statements of the questionnaire. 6- point Likert scale was used for the questionnaire with number 1 indicating "strongly disagree" and number 6 implying "strongly agree".

\section{Procedures}

Having gathered the necessary data, we took several steps to analyze the data, reach the goals of the study and find the answers to the posed questions. Following is the description of data collection procedure in each class.

Session one: In order to check whether the students were at the same level of proficiency or not, the Nelson Proficiency Test at the intermediate level was used in the first session of each class.

Session two: From this session the teacher started to teach each class, one based on the principles of TBLT and the other one on the basis of the PPP approach. The session was devoted to make students familiar with the aims of classes, make them interested in the subject matter and answer students' questions. In TBLT class, the students had a lot of opportunity to express their ideas and ask their questions. The teacher tried to guide their speech through some questions and helped them to conclude about different lesson parts.

However, in the class based on PPP approach students had a limited role. They could participate by the allowance of the teacher who was the whole authority in the class. The teacher used some abstracts in order to explain the aims of the classes and exemplify her speech, and wrote the important points on the board such as students' responsibilities.

Sessions three to seven: These five sessions in each class were devoted to teach the five abstract moves .It means that each session was devoted to teach one of the moves. In both classes the class time was devoted to three phases. In TBLT class, these phases were pre-task, task-cycle and post-task. In the first phase the teacher tried to introduce the move, explain its place and role. The students could participate in this phase and through some questions the teacher tried to increase their participation in the class. In the next phase, the students were asked to complete tasks in groups. The teacher tried to check students' participation and answer students' questions. During the last phase, students could 
ask their questions and they were asked to read their answers and teacher tried to encourage different groups to participate in this phase.

The three phases of the class based on PPP approach were presentation, practice and production. The first phase was the teaching phase in which the students received teaching on different abstract moves. The students had a limited role and mostly were trying to take notes about the important information such as the name, place and sequence of the moves. After her explanation, the teacher gave students some examples and put them on the board. After teaching the teacher gave students the opportunity to ask their questions. The students could raise their hands and whenever the teacher allowed them they could ask their questions. Moreover, since the students had a limited role and did not participate a lot during the teaching phase, the teacher asked them several questions at the end of this phase to check whether the students comprehended the lesson well or not. In the practice phase, the students were given an activity to do individually. After completing the activity, the teacher asked them to read their answers .It was the teacher who chose students to answer the activity. If the answers were not correct, other students were chosen .The last phase was the production phase in which the students were required to write the move that was taught to them for a research article.

Session eight: All the moves were reviewed in both classes in this session and students asked their questions.

Session nine: The post-test was taken and motivation questionnaire were distributed among the students of both classes.

\section{E. Measurement}

Hyland's (2007) abstract moves analysis was used in this study for checking the results of post-test. According to him, abstracts have five moves namely: Introduction, purpose, method, result and conclusion. Since the total number of moves considered in writing an abstract was 5, students were given scores according to these 5 moves. Three criteria considered in checking the students' writings were as follows: identification and use of the moves, putting them in right places and putting them in correct sequences. The first criterion is for checking the ability of students in using the moves and since there were totally five moves, 5 scores were considered for this criterion. The aim of the second criterion was to check whether the moves are put in the right place or not. Since there were five moves and they should be placed in five places, 5 scores are considered for this criterion. The last criterion was meant to check whether the moves which are used in the writing of abstract are in correct sequence .Since there were five moves, 4 scores were considered for the correct sequence of the moves. Therefore, by applying these three criteria, students were given scores out of 14 for their writing of abstracts. Then SPSS software version 19 was used to measure the correlation between the scores the students have gained in the post-test and the scores they have been given for their motivation on the basis of the results of the completed questionnaires.

The Motivation questionnaire, we adopted from a research done by Lam and Law (2007) had 18 items which were divided into six subcategories namely, challenge, real life significance, curiosity, autonomy, recognition, and evaluation. Three items were included in each subcategory. In the questionnaire the students were asked to indicate how much they agreed that the 18 statements truly described the practices of their teachers in the writing classrooms through a 6 -point likert scale with number 1 standing for strongly disagree and number 6 indicating strongly agree. The average score of the items was used as an index of the students' perceptions of their teachers' instructional practices. High scores were an indication that the students agreed that their teacher adopted motivating instructional practices and low scores indicated that they did not believe so. After giving scores to the students based on the completed questionnaire, SPSS software was used in order to analyze the Independent-Sample T- Test.

\section{F. Design of the Study}

This research was quasi-experimental in nature because as Hatch and Farhadi (1981) explicated "the concept of experimental design is an idealized abstraction...in our field, it is not realistic to limit our research to true experimental design only" (p.23).In more details, it was a post-test non-equivalent-groups design (Best and Kahn, 2006, p.183) since there was no random assignment of the participants to experimental and control groups and the groups were naturally assembled as intact classes.

\section{RESUltS AND DiscUSSION}

Table 1 and 2 represent the results of Pearson Correlation between the scores which students have gained in writing research abstracts and the scores which they have been given according to their answer to the questionnaire. As it is clear from the table 4 , the correlation is 0 and it is significant at the 0.01 level. Therefore, the second null hypothesis was also rejected since there is a significant positive relationship between students' motivation and their performance in writing abstracts.

TABLE1.

DESCRIPTIVE STATISTICS FOR CORRELATION

\begin{tabular}{|c|c|c|c|}
\hline & Mean & Std. Deviation & $\mathrm{N}$ \\
\hline motivation & 55.09 & 13.858 & 68 \\
\hline score & 8.44 & 3.405 & 68 \\
\hline
\end{tabular}


TABLE2.

THE RESULTS OF PEARSON CORRELATION

\begin{tabular}{llll}
\hline & \multicolumn{4}{c}{ THE RESULTS OF PEARSON CORRELATION } & \\
\multirow{3}{*}{ motivation } & Pearson Correlation & 1 & score \\
& Sig. (2-tailed) & & $.783^{* *}$ \\
& $\mathrm{~N}$ & 68 & .000 \\
score & Pearson Correlation & $.783^{* *}$ & 68 \\
& Sig. (2-tailed) & .000 & 1 \\
& $\mathrm{~N}$ & 68 & 68 \\
\hline
\end{tabular}

Tables 3 and 4 show the results of the Independent Sample T-Test of the students based on the post-test. As the significance of Levene's Test is equal to .05 we cannot assume equal variances between groups .Therefore, considering the second row of the table it can be concluded that the difference between the two groups is significant at the level of .05.Therefore our null hypothesis which was "there is not a significant difference between the two groups regarding their role in helping students to write better abstracts" is rejected. As is indicated in the table, it is evident that the group of students which was taught based on TBLT principle, which comprise the experimental group, were more successful in post-test.

TABLE3.

GROUP STATISTICS FOR THE POST-TEST

\begin{tabular}{llllll}
\hline \multirow{4}{*}{ score } & group & $\mathrm{N}$ & Mean & Std. Deviation & Std. Error Mean \\
& control & 36 & 7.58 & 3.138 & .523 \\
& experimental & 32 & 9.25 & 3.654 & .646 \\
\hline
\end{tabular}

TABLE4.

INDEPENDENT SAMPLE T-TEST FOR THE POST-TEST

\begin{tabular}{|c|c|c|c|c|c|c|c|c|c|c|}
\hline & & \multicolumn{2}{|c|}{$\begin{array}{l}\text { Levene's Test for } \\
\text { Equality of } \\
\text { Variances }\end{array}$} & \multicolumn{7}{|c|}{ t-test for Equality of Means } \\
\hline & & $\mathrm{F}$ & Sig. & $\mathrm{t}$ & df & $\begin{array}{l}\text { Sig. (2- } \\
\text { tailed) }\end{array}$ & $\begin{array}{l}\text { Mean } \\
\text { Difference }\end{array}$ & $\begin{array}{l}\text { Std. Error } \\
\text { Difference }\end{array}$ & $\begin{array}{l}95 \% \mathrm{C} \\
\text { Interva } \\
\text { Differe }\end{array}$ & $\begin{array}{l}\text { ence } \\
\text { he }\end{array}$ \\
\hline score & $\begin{array}{l}\text { Equal variances assumed } \\
\text { Equal variances not assumed }\end{array}$ & 3.689 & .059 & $\begin{array}{l}-2.02 \\
-2.00\end{array}$ & $\begin{array}{l}66 \\
61.54\end{array}$ & $\begin{array}{l}.047 \\
.049\end{array}$ & $\begin{array}{l}-1.667 \\
-1.667\end{array}$ & $\begin{array}{l}.824 \\
.831\end{array}$ & $\begin{array}{l}\text { Lower } \\
-3.311 \\
-3.329\end{array}$ & $\begin{array}{l}\text { Upper } \\
-.022 \\
-.005\end{array}$ \\
\hline
\end{tabular}

The results showed a significant relationship between scores of students on post-test and their motivation. It can be concluded that motivated students can have better performance in writing. Moreover, , it was found out that the students of the class based on TBLT approach gained higher scores both on the post-test and motivation. It can be implied that TBLT approach was more successful in terms of motivating students and this resulted in better performance of the students in the post-test.

The teachers, as controllers and facilitators of the activity of learners in the classroom, should have enough knowledge about TBLT in order to successfully implement it. Teachers need to know how to rely on their knowledge about motivation when dealing with issues that involve motivational concerns and when making instructional decisions. Teacher skills in motivating learners should be seen as focal to teaching effectiveness since motivation is an important factor in learning. When deciding to use TBLT, instructors have to be seen as motivators and facilitators of the learning process since the idea is to make learners responsible for their own learning. According to this research, the following suggestions can be given to the teachers:

-It was reported that students display greater enthusiasm when they can relate the content and course activities or tasks to their daily lives because they see the value of what they are learning. Therefore, it can be suggested to the teachers to use some techniques such as giving clear examples from real life to make a connection between what students are learning and real world activities.

-A major task in teaching is to nurture student curiosity and use it as a motive for learning. Teachers should provide students with stimuli that are new but not much different from what they already know so as to stimulate curiosity. Therefore, there should be a kind of balance between complexity and clarity.

-Teachers should try to design assignments at a right difficulty level and at the same time challenging for the students in order to increase students' motivation in learning.

-Teachers should give students options in the classroom and empower them by giving a sense of autonomy which can increase students' motivation.

-Teachers should not create a situation in which the students compete with one another for grades.

The extremely competitive types of classroom settings can induce performance anxiety which can interfere with learning and thereby counteracting the goal of motivation. Students want to be recognized for the hard work and effort they put into their classes. Therefore, an approach which pays attention to the process of learning and pays attention to the effort of students can be more effective than an approach which pays more attention to the product.

-Teachers should provide students with useful feedbacks which can motivate students during the learning process. 
Finally, it should be noted that although there is a limit to the extent to which we can actually motivate students, we should not stop trying.

\section{CONCLUSION}

The present article aimed at examining the relationship between EFL learners' motivation and their performance in writing research abstracts as well as the impact of task-based approach on the participants' motivation. For these aims, two classes based on PPP and TBLT approaches were held. Results showed that students will be motivated when their teachers provide them with tasks which are challenging, used activities which are related to the real world, made them curious in learning new things, gave them enough autonomy, praised their efforts and gave them useful feedbacks (Lam and Law, 2007) . and TBLT approach was more successful in this regard.

The results showed a significant relationship between scores of students on post-test and their motivation. It can be concluded that motivated students can have better performance in writing research abstracts. Moreover, , it was found out that the students of the class based on TBLT approach gained higher scores both on the post-test and motivation. It can be implied that TBLT approach was more successful in terms of motivating students and this resulted in better performance of the students in the post-test. The results are useful for teacher educators who are interested in finding approaches which are motivating for the students and can help them to have a better writing performance. According to Cochran-Smith (2004, as cited in Lam and Law, 2007) one of the main problems in teacher education is its overemphasis on teachers' knowledge, skills, and beliefs but lack of enough attention to students' learning. The present study attempted to respond to the need of investigating teachers' behaviors in classrooms as related to students' learning outcome. The research showed that although the motivation is a personal matter, it can be influenced by external factors such as the approach of teaching in use. Therefore, teachers should do their best to make students motivated in language learning. Moreover, educators must keep the principles of motivation at the fore front of all instructional design.

Finally, it should be mentioned that no study is complete by itself and cannot take all details into consideration. Therefore, there are always aspects which are not accounted for. This research is no exception. There are some issues which were not considered in this study and can be topics for further research by other researchers. At first, the data for understanding students' motivations in writing was only collected through a questionnaire; some other studies can be carried out to incorporate interviews with students as well. Furthermore, the participants were adult learners; in other studies language learners in other ages can be the focus of attention to see whether similar results will be obtained. Moreover, due to the time limitation a few number of tasks and activities were used in this study, other studies can be done with the focus on different types of tasks and activities. To further investigate the relationship among teaching approaches and students' motivation, more studies should be conducted.

\section{APPENDIX}

\section{A. The Questionnaire}

How much do you agree that the following statements accurately describe the practices of your teacher in the writing lesson?

Challenge

1. Our teacher started with the easy concepts and progressively guided us through the difficult ones when teaching us how to write.

2. Our teacher gave us writing assignments at the right level, neither too difficult nor too easy.

3. Our teacher, noting our failure to comprehend a subject, tried alternative teaching approaches until we understood.

Real life significance

1. Our teacher pointed out the relation between this genre of writing and our everyday life.

2. Our teacher pointed out the advantages of learning this genre of writing.

3. Our teacher helped us to understand that learning this genre of writing is not just for meeting course requirements but also for practical use.

Curiosity

1. Our teacher aroused our curiosity and interest before teaching us how to write.

2. Our teacher raised some difficult questions in discussion and asked us to think them over.

3. Our teacher encouraged us to sort out the content on our own and did not provide a model answer.

Autonomy

1. Our teacher let us write freely with our own ideas.

2. Our teacher allowed us freedom to choose subject for our writing.

3. Our teacher encouraged us to write with our favorite approach.

Recognition

1. Our teacher praised not only the most successful students but also those who tried hard.

2. Our teacher encouraged us to make self-improvements and showed us that we did not need to win over others.

3. Our teacher gave recognition to students who had made progress despite the fact that they were not the best.

Evaluation 
1. Our teacher pointed out those areas that needed improvement when marking the writings.

2. Our teacher made comments or suggestions when marking the writings, rather than merely giving the grade.

3. Our teacher evaluated our achievement by how well we had written rather than how we compared with other students.

\section{B. Samples of Tasks Used in Classes Based on Task-based Approach}

1) Which of the following sentences are true about the following abstract? Why?

a) Having extra information

b) Not having some parts of information

c) Having problem in the form of writing

d) Having no problem

This study compares the performance of the same writing task by groups of four learners, pairs and individual learners. We analyzed the written texts produced and the oral interactions between the groups and the pairs as they collaborated to write their texts, in order to find an answer to the following two questions:

1) Does the number of participants in a writing task affect the accuracy, fluency, and complexity of the written texts produced?

2) Does the number of participants in the collaborative version of the writing task affect the frequency and nature of language-related episodes (LREs)?

The results showed that the text written by the groups were more accurate not only than those written individually, but also than those written in pairs.

2) Find the extra information in the following abstract:

The majority of research to date on pre-task planning has investigated the impact of planning time on L2 learners' oral production, and has generally reported its positive effects on their task performance .However, little research on planning has been conducted in writing contexts, and there is no firm evidence to demonstrate that pre-task planning promotes L2 learners' written production in the ways that many researchers have reported for L2 speaking context. What can be said from the research to date is that advance planning time itself does not seem to have much effect on L2 learners' output in writing. This is different from the research on speaking, which generally shows that learners' oral production may improve by simply allowing them time to plan before speaking. In this paper, I have explored whether and how concept mapping as a form of pre-task planning could benefit the writing performance of three Japanese ESL learners. Concept mapping was first developed by Hanf(1971). I analyzed four compositions from each of the learners, written with and without concept mapping; using measures of accuracy, complexity, fluency and [Hamp-Lyons, L., 1991. Reconstructing "academic writing proficiency". In: Hamp-Lyons L. (Ed.), Assessing second language writing in academic contexts.Ablex,Norwood,NJ,PP.127-153.] holistic measures of global quality, communicative quality, organization, argumentation, linguistic accuracy, and linguistic appropriacy. I also examined through a questionnaire, retrospective interview, and logs, the learners' applications of the strategy in their writing processes.

B. SAMPLES OF ACTIVITIES USED IN CLASSES BASED ON PRESENTATION-PRACTICE-PRODUCTION APPROACH

\section{1) Find the abstract's moves in the following text and write their names above them:}

Previous research from the perspective of the sociocultural theory of mind suggests that writing tasks completed in pairs offer learners an opportunity to collaborate in the solution of their language-related problems, co-construct new language knowledge, and produce linguistically more accurate written texts. Building on this research, the present study compares the performance of the same writing task by groups of four learners $(n=15)$, pairs $(n=15)$, and individual learners $(n=21)$.It examines the effect of the number of participants on the fluency, complexity, and accuracy of the written texts produced, as well as the nature of the oral interaction between the pairs and the groups as they collaborate throughout the writing process. The analysis of interaction focused on language-related episodes (LREs) reveals that although both groups and pairs focused their attention on language relatively often, groups produced more LREs and a higher percentage of correctly resolved LREs than pairs. As a result, the texts written by the groups were more accurate not only than those written individually, but also than those written in pairs. The implications of these results for the understanding of both collaborative writing tasks and collaborative problem solving activity are discussed.

\section{2) Find different parts of moves in the following sentences and order them.}

I analyzed four compositions from each of the learners, written with and without concept mapping; using measures of accuracy, complexity, fluency and [Hamp-Lyons, L., 1991. Reconstructing "academic writing proficiency". In: HampLyons L. (Ed.), Assessing second language writing in academic contexts.Ablex,Norwood,NJ,PP.127-153.] holistic measures of global quality, communicative quality, organization, argumentation, linguistic accuracy, and linguistic appropriacy.

However, little research on planning has been conducted in writing contexts, and there is no firm evidence to demonstrate that pre-task planning promotes L2 learners' written production in the ways that many researchers have reported for $\mathrm{L} 2$ speaking context.

The majority of research to date on pre-task planning has investigated the impact of planning time on L2 learners' oral production, and has generally reported its positive effects on their task performance. 
In this paper, I have explored whether and how concept mapping as a form of pre-task planning could benefit the writing performance of three Japanese ESL learners.

Moreover, each learner made unique applications of the concept mapping strategy in their writing processes, suggesting that concept mapping may help ESL learners improve their composing but in ways unique to individual experience, motivation, and task conditions.

I also examined through a questionnaire, retrospective interview, and logs, the learners' applications of the strategy in their writing processes.

Pre-task planning was associated positively with the overall measures of the learners' written production during inclass compositions, with the exception of accuracy.

\section{REFERENCES}

[1] Adams, R., \& Newton, J. (2009).TBLT in Asia: Constraints and opportunities. Asian Journal of English Language Teaching, 19, 1-17.

[2] Best, J.W., \& Kahn, J.V. (2006). Research in education ( $10^{\text {th }}$ ed).Boston: Pearson Education, Inc.

[3] Boekaerts, M. (2002). Motivation to learn. France: SADAG Publication.

[4] Bruning, R., \& Horn, C. (2000). Developing motivation to write. Educational Psychologist, 35, 25-37.

[5] Canilao, M.L.E.N. (2009).Mission possible: How to make Writing more meaningful and fun for learners. ELT World Online, 1, $1-8$.

[6] Carless,D.(2009).Revisiting the TBLT versus P-P-P debate: Voices from Hong Kong. Asian Journal of English Language Teaching, 19, 49-66.

[7] Dörnyei, Z. (1998) .Motivation in second and foreign language learning. Language Teaching, 31, 117-135.

[8] Dweck, C.S. (1986).Motivational process affecting learning. American Psychologist. 41 (10). 1040-1048.

[9] Ellis,R.(2009).Task-based language teaching :Sorting out the misunderstandings. International journal of Applied Linguistics, 19(3), 221-246.

[10] Hatch, E. \& Farhadi, H. (1981). Research design and statistics for applied linguistics. Tehran: Rahnama Publication.

[11] Hidi, S. \& Boscolo, P. (Ed.) (2007).Writing and motivation. The Netherlands: Elsevier Ltd.

[12] Hyland, K. (2000). Disciplinary discourses: Social interactions in academic writing. Harlow: Longman.

[13] Izadpanah, S. (2010).A study on task-based language teaching: from theory to practice.US-China Foreign Language, 8(3), 4756.

[14] Jong, I. (2006). EFL teachers' perceptions of Task-based language teaching: with a focus on Korean secondary classroom practice. Asian EFL Journal, 8(3), 192-206.

[15] Kassabgy, O., Boraie, D., \& Schmidt, R. (2001). Values, rewards, and job satisfaction inESL/EFL. In Z. Dörnyei \& R. Schmidt (Eds.), Motivation and second language acquisition (Technical Report \#23, pp. 213-237). Honolulu: University of Hawai'i, Second Language Teaching and Curriculum Center.

[16] Keihaniyan,M.(2009).Teaching methodology, motivation, and test anxiety: Comparison of Iranian English private institute and high school. In: Reinet, R (Ed.). Into the next decade with FL teaching. Japan: Roudolf Reinelt Research .

[17] Lam,S.F.,\& Law,Y.K. (2007).The roles of instructional practices and motivation in writing performance. Journal of Experimental Education, 75(2), 145-164.

[18] McClintic,S.V. (1989). Motivational factors related to writing instruction in classrooms using process and product oriented approaches. Paper presented at the Annual Meeting of the American Research Association, San Francisco, CA. ERIC.ED308522.

[19] Murad,T.M. (2009). The effect of task-based language teaching on developing speaking skills among the Palestinian secondary EFL students in Israel and their attitudes towards English Unpublished Ph.D. thesis. Yarmouk University, Irbid, Jordan.

[20] Nunan, D. (2006). Task-based language teaching in Asia context: Defining 'task'. Asian EFL Journal, 8(3), 1-4.

[21] Ripple, R.E. (1965).Affective factors influence classroom learning. Educational Leadership. 22(7)476-480.

[22] Skehan, P. (1996). A framework for the implementation of task-based instruction. Applied linguistics, 17(1), 38-62.

[23] Swales, J (1990). Genre analysis: English in academic and research settings. Cambridge: Cambridge University Press.

[24] Swan, M. (2005). Legislation by hypothesis: the case of task-based instruction. Oxford: Oxford University Press.

[25] Takahashi,S.(2005). Pragmalinguistic awareness: Is it related to motivation and proficiency? Applied Linguistics, 26(1), 90-120.

[26] Vystavêloà, L. (2009). Common EFL methods applied at language schools in the Czech Republic: PPP or TBLT unpublished master's thesis. Masaryk University, Czech Republic.

[27] Waege, K. \& Pantziara, M. (2010). Students' motivation and teachers' practices in the mathematics classroom. Retrieved July 10 from http://cerme8.metu.edu.tr/wgpapers/WG8/WG8_Waege.pdf.

[28] Wentzel, K. \& Wigfield, A. (1998). Academic and social motivational influences on students' academic performance. Education Psychology Review, 10(2).155-175.

Masoud Khalili Sabet is Assistant Professor of TEFL and the assistant director of research and technology at University of Guilan, Rasht, Iran. His research interests include advanced writing, methodology of language teaching, language teaching in practice, and testing. 
Abdorreza Tahriri is Assistant Professor of TEFL at University of Guilan, Rasht, Iran. He has many publications and conference presentations on different subjects related to TEFL. His main areas of interest include differentiated instruction, critical thinking and computer-assisted language learning.

Eshrat Bazarmaj Haghi is an M.A. student of TEFL at University of Guilan, Rasht, Iran. Her research interest includes Language skills and components, book evaluation, teacher development, Task-based language teaching. 